\title{
Fisioterapia na saúde da mulher: acesso à informação para melhoria da sexualidade de mulheres jovens
}

\author{
Physiotherapy in women's health: access to information to improve the sexuality of young women \\ Fisioterapia en la salud de la mujer: acceso a la información para mejorar la sexualidad de las jóvenes
}

\begin{abstract}
RESUMO
OBJETIVO: compreender por que e quais as motivações levam as mulheres jovens a buscarem informações sobre sexualidade e autoconhecimento através das redes sociais. MÉTODO: trata-se de pesquisa de abordagem qualitativa, com participação de 35 mulheres com idades entre 20 e 35 anos. Para coleta de dados, optou-se pela aplicação de questionário semiestruturado e a análise de dados seguiu as propostas de Bardin. RESULTADO: identificou-se que a internet é uma das formas mais utilizadas na busca de informações sobre sexualidade feminina devido à falta de liberdade que as mulheres jovens têm em se comunicar com a família ou profissionais especialistas. CONCLUSÃO: as redes sociais são uma importante ferramenta para educação sexual, pois leva as mulheres a terem curiosidade de conhecerem o próprio corpo e tratarem o tema sexualidade como algo comum, evitando traumas, desenvolvimento de disfunções, degradação da saúde física, sexual e mental.
\end{abstract}

Descritores: Fisioterapia; Saúde da Mulher; Sexualidade; Rede Social.

\section{ABSTRACT}

OBJECTIVE: To understand why and what motivates young women to seek information about sexuality and self-knowledge through social networks. METHODS: This is a qualitative research, with the participation of 35 women aged between 20 and 35 years. For data collection, we chose to apply a semi-structured questionnaire and data analysis followed Bardin's proposals. RESULT: It was identified that the internet is one of the most used ways to search for information about female sexuality due to the lack of freedom that young women have in communicating with family or professional specialists. CONCLUSION: Social networks are an important tool for sexual education, because it leads women to be curious about their own bodies and to treat the topic of sexuality as something common, avoiding traumas, development of dysfunctions, degradation of physical, sexual and mental health.

Descriptors: Physiotherapy; Women's Health; Sexuality; Social Network.

\section{RESUMEN}

OBJETIVO: comprender por qué y qué motivaciones llevan a las jóvenes a buscar información sobre sexualidad y autoconocimiento a través de las redes sociales. MÉTODOS: Se trata de una investigación cualitativa, con la participación de 35 mujeres de entre 20 y 35 años. Para la recogida de datos, se optó por la aplicación de un cuestionario semiestructurado y el análisis de los datos siguió las propuestas de Bardin. RESULTADO: Se identificó que internet es una de las formas más utilizadas en la búsqueda de información sobre la sexualidad femenina debido a la falta de libertad que tienen las jóvenes para comunicarse con la familia o los profesionales especialistas. CONCLUSIÓN: las redes sociales son una herramienta importante para la educación sexual, ya que lleva a las mujeres a sentir curiosidad por su propio cuerpo y a tratar el tema de la sexualidad como algo común, evitando traumas, desarrollo de disfunciones, degradación de la salud física, sexual y mental. Descriptores: Fisioterapia; Salud de La Mujer; Sexualidad; Red Social.

RECEBIDO EM: 15/07/2021 APROVADO EM: 10/08/2021 


\section{artigo}

Damasceno, A. M. B., Riani, P. L. L., Flisch, P. C., Fonseca, D. F., Martins, I. L., Faria, S. C. A.

Fisioterapia na saúde da mulher:acesso à informação para melhoria da sexualidade de mulheres jovens

ANA MARIA BARBOSA DAMASCENO

Bióloga, Doutora em Saúde Pública pela Universidade de Ciências Empresariais e Sociais. Bueno Aires. Argentina. Profa. do curso de Fisioterapia do Centro Universitário Presidente Antônio Carlos, Barbacena, Mg.

ORCID: 0000-0002-2320-2321

\section{PRISCYLLA LILLIAM KNOPP RIANI}

Fisioterapeuta, Doutora em Saúde Coletiva pela Universidade Federal do Rio de Janeiro. Profa. do curso de Fisioterapia do Centro Universitário Presidente Antônio Carlos, Barbacena, Mg.

ORCID: 0000-0001-6530-9365

\section{PAULA CRISTINA FLISCH}

Graduanda em Fisioterapia do Centro Universitário Presidente Antônio Carlos, Barbacena, Mg. ORCID: 0000-0001-6079-017X

\section{DANÚBIA DE FARIA FONSECA}

Graduanda em Fisioterapia pelo Centro Universitário Presidente Antônio Carlos, Barbacena, Mg. ORCID: 0000-0003-1329-7061

\section{ISABELA LEME MARTINS}

Graduanda em Fisioterapia pelo Centro Universitário Presidente Antônio Carlos, Barbacena, Mg. ORCID: 0000-0001-5490-7730

\section{SAMARA CRISTIANE DE ARAÚJO FARIA}

Graduanda em Psicologia pelo Centro Universitário Presidente Antônio Carlos, Barbacena, Mg. ORCID: 0000-0001-7518-6960

\section{INTRODUÇÃO}

Durante muitos anos, a sexualidade feminina foi moldada por padrões morais, éticos e comportamentais dentro do contexto cultural, social e familiar e entendida como inexistente. Grande parte das mulheres não se dava conta do quanto isso as afetaval, 2.

$\mathrm{O}$ contexto religioso apregoava que as mulheres deveriam ter seus desejos abafados e reprimidos desde muito cedo. As dúvidas sobre sexo geravam constrangimento e se as mulheres desejassem algo a mais, lhe vinha, de forma consciente ou inconsciente, o sentimento de erro e culpa por coisas que deveriam ser completamente normais1,2.

Após as duas grandes guerras as mulheres começaram a ganhar autonomia e, a partir disso, o tema sexualidade foi sendo mais questionado entre elas. Neste período as mulheres começaram a conquistar sua independência, o que gerou convívio e troca de experiências3, além da introdução da pílula anticoncepcional em 1960, a qual se-

\section{O contexto}

religioso apregoava

que as mulheres

deveriam ter seus

desejos abafados e

reprimidos desde

muito cedo. parou o sexo produtivo do sexo prazeroso4.

De acordo com a Organização Mundial da Saúde, a sexualidade é "uma energia que nos motiva para encontrar amor, contato, ternura e intimidade; ela integra-se no modo como sentimos, movemos, tocamos e somos tocados, é ser-se sensual e ao mesmo tempo ser-se sexual. A sexualidade influencia pensamentos, sentimentos, ações e interações e, por isso, influencia também a nossa saúde física e mental" 5 .

A sexualidade feminina é mais complexa que a masculina, já que possui suas características próprias, que a tornam diferente. No caso das mulheres, possuem emoções e necessidades básicas que precisam ser apreciadas e satisfeitas. $\mathrm{E}$ isso se deve ao aspecto fisiológico, que proporciona à mulher uma capacidade maior de experimentar e sentir seu próprio corpo 2 .

As redes sociais se tornam um forte aliado para as mulheres, afim de levar informaçōes sobre autoconhecimento e sexualidade devido a possível falta de trocas de experiências entre familiares e/ou profissionais da 
saúde6. Como a sociedade contemporânea exige respostas rápidas, as redes sociais surgem como elemento potencializador de tais processos.

Atualmente essa temática tem conquistado bastante espaço no mundo feminino e vem se apresentando como algo que deve ser exposto e dialogado inclusive através das mídias sociais6,7. Frente a isso, tem-se visto muitos profissionais da saúde, dentre eles, os fisioterapeutas, que estão utilizando as redes sociais para promover a saúde sexual das mulheres e dar acesso a informações sobre autoconhecimento7.

Acredita-se que está havendo um aumento na procura de informações sobre esta temática através das redes sociais devido à falta de diálogo junto à família ou profissionais especialistas desta área de saúde5,7. Essa redução de informações pode afetar a sexualidade e, consequentemente, piorar a qualidade de vida dessas mulheres.

Considerando que, quando a mídia veicula informações ao público feminino, exista uma conexão entre as redes sociais e sua influência no comportamento das mulheres em relação à sexualidade, este estudo tem o seguinte objetivo: compreender por que e quais as motivações levam as mulheres jovens a buscarem informações sobre sexualidade e autoconhecimento através das redes sociais.

\section{MÉTODOS}

Trata-se de uma pesquisa com abordagem qualitativa, a qual, de acordo com $\mathrm{Mi}$ nayo, trabalha com o universo de significados, motivos, aspirações, crenças, valores e atitudes não se importando se as amostras são relativamente pequenas8.

A coleta de dados foi feita nos meses de fevereiro a abril de 2021 com a participação de 35 mulheres com idades entre 20 e 35 anos de idade. O convite de participação foi feito através da publicação nas redes sociais. Foram excluídas mulheres que não possuíam acesso às mídias digitais.

A primeira abordagem às mulheres foi para explicar sobre a pesquisa e para assinatura do Termo de Consentimento Livre e Esclarecido. O questionário foi aplicado em local reservado, de escolha da participante, preservando o anonimato e a privacidade. Cabe destacar que alguns questionários foram realizados através de videochamadas e gravadas em áudio devido à distância entre as cidades ou por escolha das entrevistadas

O benefício desse estudo se refere ao desenvolvimento do conhecimento científico na área de estudos da Fisioterapia na Saúde da Mulher, bem como a compreensão da importância das redes sociais na disseminação do conhecimento sobre autoconhecimento e da sexualidade entre as mulheres jovens. $\mathrm{O}$ risco relacionado à execução desta pesquisa seria o constrangimento em relatar alguma informação.

Como instrumento de coleta optou-se por questionário semiestruturado, previamente elaborado pelas pesquisadoras. A análise dos dados teve como suporte metodológico a análise de conteúdos proposta por Bardin9 através dos seguintes passos: 1) Transcrição das entrevistas; 2) Unitarização dos textos, com a redução do texto em paráfrases; 3) Sistema de categorização; 4) Interpretação dos dados.

As observaçôes tiveram como alvo identificar a percepção sobre autoconhecimento e sexualidade das mulheres entrevistadas, tentando compreender os "conflitos e tensões" existentes, atentando para os aspectos éticos, tradições, costumes, sentimentos e relações sociais.

Esta pesquisa atendeu aos preceitos da resolução 510/1610, foi aprovada após análise do Comitê de Ética em Pesquisa/UNIPAC CAAE: 40687820.1.0000.5156, com parecer de aprovação número 4.476.357.

\section{RESULTADOS}

Percepção das mulheres sobre a busca de informações relacionadas ao autoconhecimento e sexualidade junto à família.

A análise desta categoria demonstrou que há e dificuldade de comunicação entre as mulheres e suas famílias acerca desse tema.

"Porque em casa não posso conversar sobre este assunto, minha mãe é muito das antigas, foi criada por namoros que eram apenas mãozinhas dadas, por isso não tenho liberdade para falar disso com ela." (B1)

É possível salientar que se faz presente à lógica da reprodução prevalecendo formas veladas de liberdade. A busca pelo pleno desempenho e prazer sexual permanecem distantes de se concretizarem, o que pode ser produto da falta de fortalecimento do autoconhecimento, bem como a necessidade do saber que é encoberto devido ao histórico de preconceito vivido pelas mulheres 11 .

Os depoimentos mostraram que as mulheres somente despertaram a curiosidade sobre o assunto após a prática do ato sexual com parceiro(a) e/ou através de pessoas não preparadas para falar sobre o assunto de forma correta, como por exemplo, através de amigos, indústria pornográfica ou primeiro parceiro sexual.

"Percebi que precisava me conbecer mais quando tive minha primeira relação sexual, foi horrivel, pois tanto eu como o parceiro não sabia nada $\{\ldots\} "(B 1)$

"Na escola a gente sempre estava comentando alguma coisa, contando uma para outra sobre mudanças do corpo." (B4)

O assunto sexualidade e/ou autoconhecimento na maioria das vezes lhes é apresentado de maneira indecorosa, sendo as mulheres obrigadas a se descobrirem sozinhas na fase da adolescência ou após a vida adulta12.

Percepção de mulheres que usam as redes sociais para pesquisar sobre sexualidade.

Identificou-se que a maioria das mulheres ainda não sabem onde e o que procurar sobre o tema. Destaca-se o conhecimento insuficiente sobre o próprio corpo, a barreira do tabu e a vergonha de fazerem algo que antes se via como pecaminoso.

"Ah não sei, eu sei que não me co- 


\section{artigo}

Damasceno, A. M. B., Riani, P. L. L., Flisch, P. C., Fonseca, D. F., Martins, I. L., Faria, S. C. A

Fisioterapia na saúde da mulher: acesso à informação para melhoria da sexualidade de mulheres jovens

nheço. Acho que a gente já vem de uma cultura que somos reprimidas nesse ponto. Acho que eu tenho vergonha ou acho que seja por falta de informaçōes." (A4)

As redes sociais foram benéficas durante os ciclos de autoconhecimento como também para saúde física e emocional, como mostrado no relato abaixo:

"\{...\}O que eu conbeci foi depois que eu entrei nas redes sociais, que a gente vê muitas coisas falando sobre isso na internet, né?" (C1)

Porém, as entrevistas mostraram que as redes sociais, sendo instagram e youtube as mais citadas, são mais eficazes como "porta de entrada" para assuntos que antes eram desconhecidos por essas mulheres e partir das novas informações, surge a curiosidade em aprofundar no assunto através da internet ou troca de experiências com profissional e /ou amigos.

Os estigmas existentes acerca da sexualidade criam barreiras para que as pessoas conversem sobre tal assunto2, pois as entrevistas, assim como outros estudos 7 , mostram que mulheres acham mais fácil divulgar informações sobre diversos assuntos ou até sobre si mesmas online, pois não requer o contato direto.

"Tem pessoas que não conseguem realmente falar ou usam isso pelo anonimato, pois para você fazer uma pergunta na internet você não precisa exatamente especificar quem é você e tem pessoas que tem dúvidas \{...\}." (B3)

Percepção das mulheres jovens frente aos profissionais da área da saúde da mulher

Outro motivo identificado para busca sobre autoconhecimento e sexualidade foi falta de abertura sobre o tema em consultas com especialistas, como demonstra os relatos abaixo:

"Os especialistas não perguntam como está o sexo, somente como eu faço sexo, parece que eles se preocupam mais com o aspecto fisiológico do que tudo." (A3).

“\{...\}Tive somente uma ginecologista que me perguntou sobre a sexualidade e foi na minha primeira consulta ginecológica, quando eu não era mais virgem e aí a ginecologista perguntou na frente da minha mãe se eu era virgem e foi muito constrangedor e depois que eu fiquei mais velha nenhum mais perguntou sobre minha sexualidade e isso me faz buscar mais sobre sexualidade." (A1).

Quanto a atuação do profissional fisioterapeuta na saúde da mulher, percebeu-se que grande parcela das entrevistadas desconhece esta área de atuação. As mulheres que apresentaram tal conhecimento fizeram ou fazem graduação em fisioterapia e este tema faz parte grade curricular do curso.

\section{DISCUSSÃO}

A pesquisa mostrou um déficit no conhecimento de mulheres jovens acerca de seu próprio corpo devido à falta de liberdade em comunicar-se com suas famílias e com profissionais especialistas sobre sexualidade e autoconhecimento.

A análise de dados e outros estudos mostram que sentimentos de vergonha $\mathrm{e}$ constrangimento são fatores de dificuldade a procura de um profissional especialista, principalmente se for homem. Para uma avaliação ou consulta é necessário tocar ou manipular áreas consideradas erógenas, no entanto, as mulheres relacionam a consulta com a sexualidade13. Por isso, existe a necessidade de estreitar os laços entre especialistas em saúde da mulher, principalmente fisioterapeutas, e pacientes, pois é uma área de interesse e relevância no mundo feminino7,14.

Portanto, as mulheres esperam e desejam um atendimento humanizado, e isso inclui questões fora do âmbito da doença, dando a elas liberdade de escolha e autonomia15, pois introduzir um modelo hu- manístico de atenção à saúde ajudaria a melhorar o conforto, a satisfação das mulheres e a reconsulta14.

$\mathrm{O}$ fato do instagram e youtube serem as redes sociais mais citadas pode ser justificado pelo fato de se tornarem uma grande ferramenta de marketing pessoal para os profissionais da área da saúde16, sendo uma moeda de troca entre pacientes/ profissionais, pois as redes sociais além de estreitarem os laços e criarem um trabalho educacional não existentes na política pública de forma efetiva5,12, também levam as mulheres a criarem curiosidades acerca de seu próprio corpo, favorecendo o autoconhecimento, melhoria da sexualidade7 e consequente promoção à saúde, pois envolve a participação ativa da população.

\section{CONCLUSÃO}

Conclui-se, portanto, que as mulheres devem entender o seu próprio corpo através de fontes verídicas e especializadas. As redes sociais são uma importante ferramenta para educação sexual, levando as mulheres jovens a terem curiosidade para conhecer o próprio corpo e tratar o tema sexualidade como comum, evitando traumas, desenvolvimento de disfunções, degradação da saúde física, sexual e mental. Por isso, esse assunto deveria ser de grande relevância para saúde pública, visto que poderiam ser elaboradas políticas educacionais desde a infância, onde é iniciada a formação da sexualidade. 


\section{REFEÊNCIAS}

1. Oliveira, EL; Martins, JR; Gonçalves, JP. História da sexualidade feminina no Brasil: entre tabus, mitos e verdades. Rev. Ártemis - Estudos de Gênero, Feminismos e Sexualidades, v. 26, n. 1, p. 303-314, 2018.

2. Gozzo TO; Fustinoni SM; Barbieri, M; Roher, WM; Freitas, IA Sexualidade feminina: compreendendo seu significado. Rev. Latino-Am. Enf. V 8 (3): 84-90. Jul, 2000.

3. Zikan, IS. O Prazer Sexual Feminino na História Ocidental da Sexualidade Humana. Monografia. Universidade Cândido Mendes, 2005, 95 f. Disponivel em: (https://www.yumpu.com/pt/ document/read/12555260/o-prazer-sexual-feminino-na-historia-ocidental-da-sexualidade). Acesso em: 21 set 2021.

4. Silva, CV. Histórias de utilização de pílulas anticoncepcionais no Brasil, na década de 1960. Fundação Oswaldo Cruz. RJ, 2017. Disponivel em: (https://www.arca.fiocruz.br/bitstream/ icict/25248/2/cristiane_silva_iff_mest_2017.pdf). Acesso em 24 set 2021

5. Camargo, SAP; Neto, LFS. Sexualidade e Gênero. Rev. Fac. Ciênc Méd. Sorocaba. v.19, n.4, p. 165-166. São Paulo (PUC). 2017.

6. Maksud, Ivia. Sexualidade e mídia: discursos jornalísticos sobre o "sexual" e vida privada. Rev. Psicologia em Estudo, Maringá, v. 13, n. 4, p. 663-671, out./dez. 2008.

7. Viegas, Paula. Discurso sobre a sexualidade feminina em mídias digitais: o caso Vagina Sem Neura. Universidade Federal do Rio Grande do Sul. 2019. Disponivel em: (https://portalintercom.org. br/anais/nacional2019/resumos/R14-1388-1.pdf).

8. Minayo, MCS. (Org.). Pesquisa social: teoria método e criatividade. $17^{\mathrm{a}}$ ed. Petrópolis, RJ: Vozes, 1994.

9. Bardin, L. Análise de conteúdo. São Paulo: Edições 70. 2011.

10. Brasil. Ministério da Saúde. Conselho Nacional de Saúde. Resolução no 510, de 7 de abril de 2016. Trata sobre as diretrizes e normas regulamentadoras de pesquisa em ciências humanas e sociais. Diário Oficial da União, Brasília, DF, 24 mai 2016.

11. Filha, CX. Sexualidade feminina entre práticas divisoras: da mulher "bela adormecida" sexualmente à multiorgástica - imprensa feminina e discursos de professoras. UFMS. n.23. 2007. Disponivel em: (https://www.anped.org.br/sites/default/files/ gt23-3297-int.pdf). Acesso em 26 jun 2021.

12. Ferreira E.A; Alves, H.V; Pereira, A.V; Rodrigues D.P; Duarte M. R; Araújo R.C.B. Sexualidade na percepção de adolescentes estudantes da rede pública de ensino de Macapá. Rev. Saúde Coletiva.

\section{v.8. n.45. p. 812-816. 2018.}

13. Ferreira, MLSM. Motivos que influenciam a não-realização do exame de papanicolaou segundo a percepção de mulheres. Esc. Anna Nery Rev. Enferm, 2009. v.13, n.2. p 378-384.

14. Pivetta, HMF; Tonello, T; Bianchini, VGP. A fisioterapia na atenção à saúde da mulher: como ela vem sendo percebida? Rev. Fisioterapia Brasil, v.1. n6. p. 417-422. 2010.

15. Paiva, ACPC.; Salimena, AMO; Souza, IEO.; Melo, MCSC.; Amorim, TV. Ambiguidade e falatório na relação assistencial: a mulher com câncer de mama e a enfermagem. Rev. Saúde Coletiva. v.9. n.47. p 1084-1088. 2019.

16. Morais, NSD; Brito, MLA. Marketing digital através da ferramenta Instagram. Rev. eacademica. v.1, n.1, ed 3. Abr, 2020. 